\title{
Correction to: The absence of the $\mathrm{drhm}$ gene is not a marker for human-pathogenicity in European Anaplasma phagocytophilum strains
}

Denis B. Langenwalder ${ }^{1}$, Sabine Schmidt ${ }^{1}$, Cornelia Silaghi ${ }^{2}$, Jasmin Skuballa ${ }^{3}$, Nikola Pantchev ${ }^{4}$, Ioana A. Matei ${ }^{5}$, Andrei D. Mihalca ${ }^{5}$, Urs Gilli', Joanna Zajkowska ${ }^{7}$, Martin Ganter ${ }^{8}$, Tove Hoffman' ${ }^{9}$, Erik Salaneck ${ }^{10}$, Miroslav Petrovec ${ }^{11}$ and Friederike D. von Loewenich ${ }^{1 *}$

\section{Correction to: Parasites Vectors (2020) 13:238} https://doi.org/10.1186/s13071-020-04116-z

Following publication of the original article [1], the author flagged that unfortunately there are errors in some of the figures and additional files.

The color-coding in Figs. 1 and 2, and in Additional file 3: Figure S1 and Additional file 4: Figure S2 is wrong: Bison samples are displayed in dark blue instead of light blue.
In addition, some numbers for the atp $A$ alleles in Additional file 1: Table S1 are wrong.

The corrected versions of Figs. 1 and 2, and Additional files 1, 3 and 4 are provided in this correction.

The authors apologize for the inconvenience caused.

*Correspondence: friederike.loewenich@unimedizin-mainz.de

${ }^{1}$ Department of Medical Microbiology and Hygiene, Medical Center

of the Johannes Gutenberg-University Mainz, Obere Zahlbacherstrasse 67, 55131 Mainz, Germany

Full list of author information is available at the end of the article

(c) The Author(s) 2020. This article is licensed under a Creative Commons Attribution 4.0 International License, which permits use, sharing, adaptation, distribution and reproduction in any medium or format, as long as you give appropriate credit to the original author(s) and the source, provide a link to the Creative Commons licence, and indicate if changes were made. The images or other third party material in this article are included in the article's Creative Commons licence, unless indicated otherwise in a credit line to the material. If material is not included in the article's Creative Commons licence and your intended use is not permitted by statutory regulation or exceeds the permitted use, you will need to obtain permission directly from the copyright holder. To view a copy of this licence, visit http:/creativeco mmons.org/licenses/by/4.0/. The Creative Commons Public Domain Dedication waiver (http://creativecommons.org/publicdomain/ zero/1.0/) applies to the data made available in this article, unless otherwise stated in a credit line to the data. 


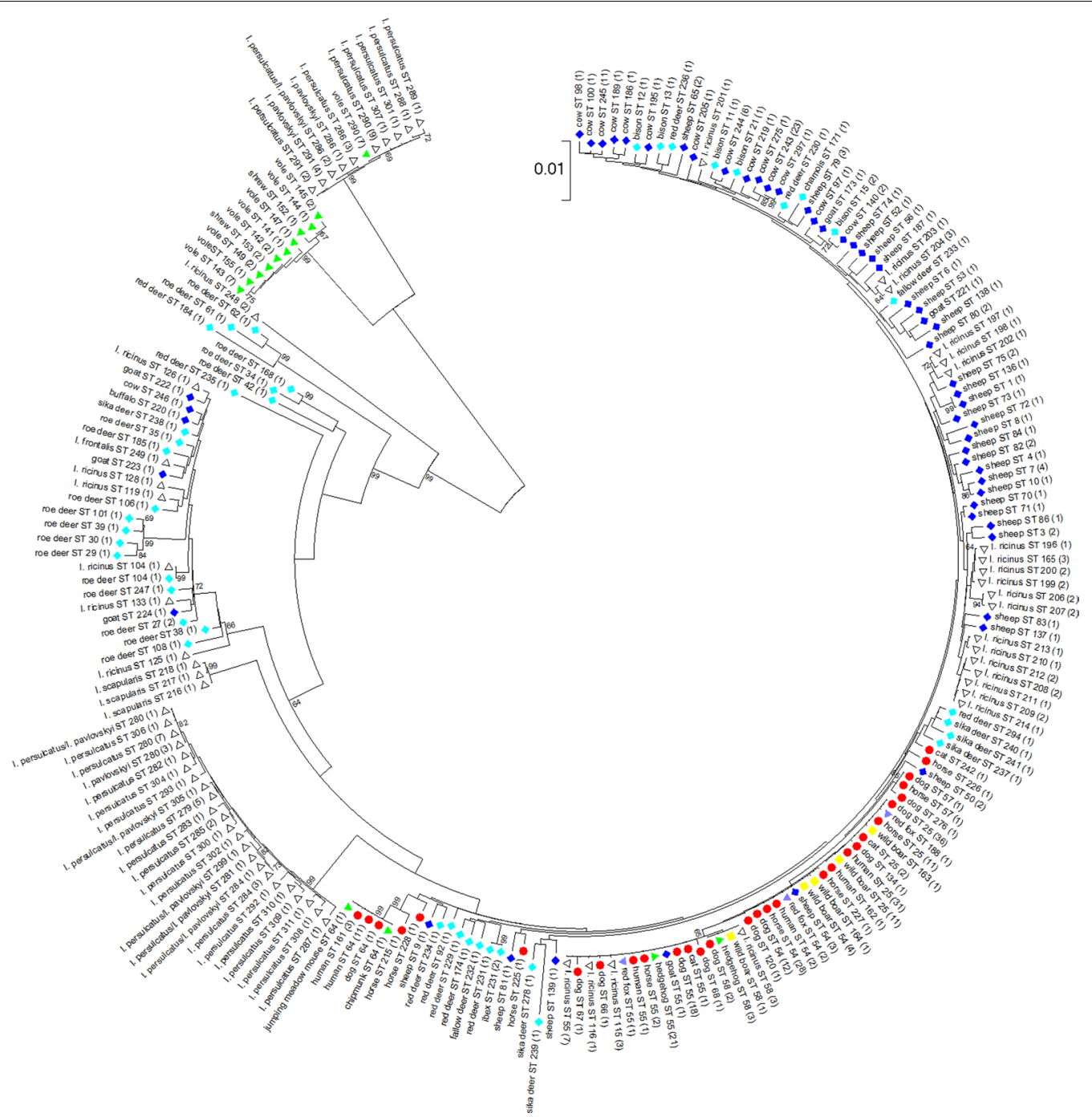

Fig. 1 Phylogenetic tree calculated from the concatenated housekeeping gene sequences of 520 samples without ambiguous nucleotides. Tree construction was achieved by the NJ method using the Jukes-Cantor matrix with the complete deletion option. Bootstrap values $\geq 64 \%$ are shown next to the branches. The scale-bar indicates the number of nucleotide substitutions per site. The final data set contained 2877 positions. Identical ST are displayed only once per species. The number in parenthesis indicates the frequency with which the respective ST was found. Key: red circles, sequences from humans, dogs, horses and cats; dark blue diamonds, sequences from domestic ruminants (cattle, sheep, goats and water buffalo); light blue diamonds, sequences from wild ruminants (roe deer, red deer, sika deer, fallow deer, European bison, mouflon, chamois and ibex); green triangles, sequences from small mammals (hedgehogs, voles, shrews, chipmunk and jumping meadow mouse); yellow squares, sequences from wild boars; purple triangles, sequences from red foxes; white triangles, sequences from ticks 


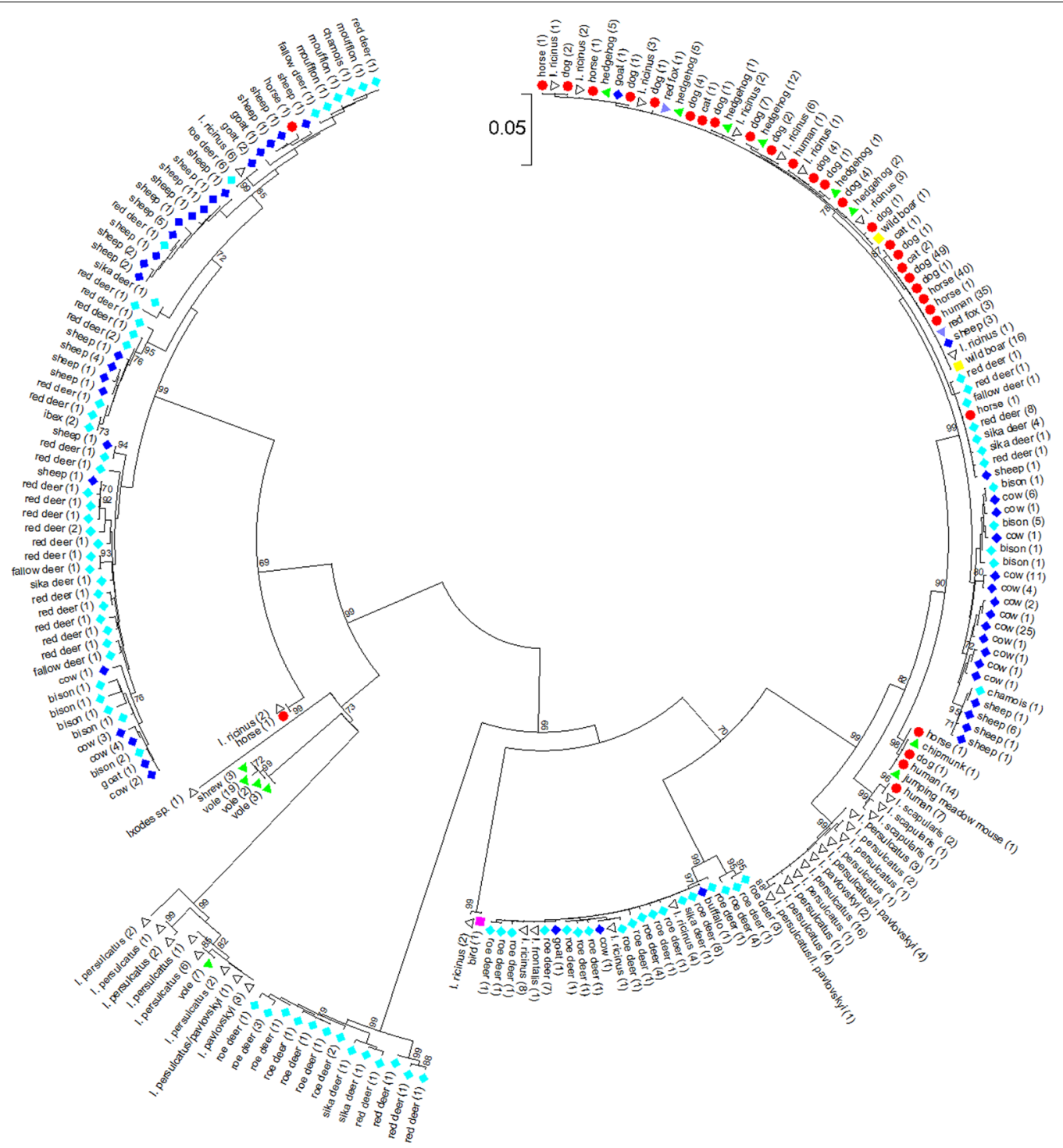

Fig. 2 Phylogenetic tree calculated from the ankA sequences of 623 samples without ambiguous nucleotides. Tree construction was achieved by the NJ method using the Jukes-Cantor matrix with the complete deletion option. Bootstrap values $\geq 69 \%$ are shown next to the branches. The scale-bar indicates the number of nucleotide substitutions per site. The final data set contained 510 positions. Identical ankA sequences are displayed only once per species. The number in parenthesis indicates the frequency with which the respective sequence was found. Key: red circles, sequences from humans, dogs, horses and cats; dark blue diamonds, sequences from domestic ruminants (cattle, sheep, goats and water buffalo); light blue diamonds, sequences from wild ruminants (roe deer, red deer, sika deer, fallow deer, European bison, mouflon, chamois and ibex); green triangles, sequences from small mammals (hedgehogs, voles, shrews, chipmunk and jumping meadow mouse); yellow squares, sequences from wild boars; purple triangles, sequences from red foxes; pink square, sequence from a bird, white triangles, sequences from ticks 


\section{Supplementary information}

Supplementary information accompanies this paper at https://doi. org/10.1186/s13071-020-04350-5.

Additional file 1: Table S1. Reference, host species, ST, CC, MLST cluster, allele numbers, ankA gene cluster, drhm status, APH_0919/APH_0922 status, country of origin, year of sampling, disease state of the host and GenBank accession numbers for the 686 A. phagocytophilum strains.

Additional file 3: Figure S1. Phylogenetic tree calculated from the concatenated housekeeping gene sequences of 520 samples without ambiguous nucleotides. Tree construction was achieved by the NJ method using the Jukes-Cantor matrix with the complete deletion option. Bootstrap values $\geq 64 \%$ are shown next to the branches. The scale-bar indicates the number of nucleotide substitutions per site. The final data set contained 2877 positions. Identical ST are displayed only once per species. The number in parenthesis indicates the frequency with which the respective ST was found. Key: red circles, sequences from humans, dogs, horses and cats; dark blue diamonds, sequences from domestic ruminants; light blue diamonds, sequences from wild ruminants; green triangles, sequences from small mammals; yellow squares, sequences from wild boars; purple triangles, sequences from red foxes; white triangles, sequences from ticks.

Additional file 4: Figure S2. Phylogenetic tree calculated from the ankA sequences of 623 samples without ambiguous nucleotides. Tree construction was achieved by the NJ method using the Jukes-Cantor matrix with the complete deletion option. Bootstrap values $\geq 69 \%$ are shown next to the branches. The scale-bar indicates the number of nucleotide substitutions per site. The final data set contained 510 positions. Identical ankA sequences are displayed only once per species. The number in parenthesis indicates the frequency with which the respective sequence was found. Key: red circles, sequences from humans, dogs, horses and cats; dark blue diamonds, sequences from domestic ruminants; light blue diamonds, sequences from wild ruminants; green triangles, sequences from small mammals; yellow squares, sequences from wild boars; purple triangles, sequences from red foxes; pink square, sequence from a bird, white triangles, sequences from ticks.

\section{Author details}

${ }^{1}$ Department of Medical Microbiology and Hygiene, Medical Center of the Johannes Gutenberg-University Mainz, Obere Zahlbacherstrasse 67, 55131 Mainz, Germany. ${ }^{2}$ Institute of Infectology, Friedrich-Loeffler-Institut, Südufer 10, 17493 Greifswald - Insel Riems, Germany. ${ }^{3}$ Chemical and Veterinary Investigations Office Karlsruhe (CVUA Karlsruhe), Weissenburgerstrasse 3, 76187 Karlsruhe, Germany. ${ }^{4}$ IDEXX Laboratories, Mörikestrasse 28/3, 71636 Ludwigsburg, Germany. ${ }^{5}$ Department of Parasitology and Parasitic Diseases, University of Agricultural Sciences and Veterinary Medicine of ClujNapoca, Calea Manastur 3-5, Cluj-Napoca 400372, Romania. ${ }^{6}$ IDEXX Diavet AG, Schlyffistrasse 10, 8806 Bäch, Switzerland. ${ }^{7}$ Department of Infectious Diseases and Neuroinfections, Medical University of Białystok, ul.Żurawia 14, Białystok 15-345, Poland. ${ }^{8}$ Clinic for Swine and Small Ruminants, University of Veterinary Medicine Hannover, Bischofsholer Damm 15, 30173 Hannover, Germany. ${ }^{9}$ Department of Medical Biochemistry and Microbiology (IMBIM), Zoonosis Science Center, Uppsala University, Uppsala, Sweden. ${ }^{10}$ Department of Medical Sciences, Zoonosis Science Center, Uppsala University, Uppsala, Sweden. ${ }^{11}$ Miroslav Petrovec, Institute of Microbiology and Immunology, Faculty of Medicine, University of Ljubljana, Zaloška 4, 1000 Ljubljana, Slovenia.

Published online: 30 September 2020

\section{Reference}

1. Langenwalder DB, Schmidt S, Silaghi C, Skuballa J, Pantchev N, Matei IA, Mihalca AD, Gilli U, Zajkowska J, Ganter M, Hoffman T, Salaneck E, Petrovec M, Loewenich FD. The absence of the drhm gene is not a marker for human-pathogenicity in European Anaplasma phagocytophilum strains. Parasites Vectors. 2020;13:238. https://doi.org/10.1186/ s13071-020-04116-z.

\section{Publisher's Note}

Springer Nature remains neutral with regard to jurisdictional claims in published maps and institutional affiliations.
Ready to submit your research? Choose BMC and benefit from:

- fast, convenient online submission

- thorough peer review by experienced researchers in your field

- rapid publication on acceptance

- support for research data, including large and complex data types

- gold Open Access which fosters wider collaboration and increased citations

- maximum visibility for your research: over 100M website views per year

At BMC, research is always in progress.

Learn more biomedcentral.com/submissions 